\title{
Research Paper: The Effect of Selected Core Stabil- ity and Hopping Exercise on Trunk Endurance and Balance of Female Kabaddi Athletes
}

\author{
Zohreh Torbatinezhad $^{1}$ Q, Hassan Daneshmandi² ${ }^{2}$, Seyyed Majid Tabatabaeinezhad²*
}

1. Department of Corrective Exercise and Sport Injuries, Sport Pathology and Corrective Exercises, Shafagh Non-Profit University, Tonekabon, Iran. 2. Departmant of Corrective Exercise and Sport Injuries, Faculty of Physical Education and Sport Sciences, University of Guilan, Rasht, Iran.

\begin{tabular}{|c|c|}
\hline $\begin{array}{l}\text { Use your device to scan } \\
\text { and read the article online }\end{array}$ & zhad SM. The Effec \\
\hline 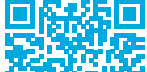 & $\begin{array}{l}\text { ercise on Trunk Endurance and Balance of Female Kabaddi Athletes. Physical Treatments. 2019; 9(2):125-136. http://dx.doi. } \\
\text { org/10.32598/ptj.9.2.125 }\end{array}$ \\
\hline 口 & d cl" http://dx.doi.org/10.32598/ptj.9.2.125 \\
\hline
\end{tabular}

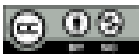

Article info:

Received: 13 Dec 2018

Accepted: 10 Feb 2019

Available Online: 01 Apr 2019
Keywords:

Kabaddi, Core stability, Hopping, Trunk endurance, Static balance, Dynamic balance

\section{A B S T RA C T}

Purpose: This study aimed to evaluate the effects of a selected course of the core stabilization of body and hopping exercises on trunk strength and balance of female Kabaddi athletes.

Methods: The subjects of this study consisted of 24 female Kabaddi players, who were randomly selected and intentionally assigned to two groups; experimental group (12 persons; Mean $\pm \mathrm{SD}$ age: $16.83 \pm 1.26$ years, height: $1.61 \pm 0.04 \mathrm{~m}$, weight: $56.50 \pm 3.06 \mathrm{~kg}, \mathrm{BMI}: 21.84 \pm 1.73 \mathrm{~kg} / \mathrm{m}^{2}$, and exercise history: $05.08 \pm 1.08$ years) and control group (12 persons; Mean \pm SD age: $16.42 \pm 0.99$ years, height: $1.60 \pm 0.05 \mathrm{~m}$, weight: $59.08 \pm 8.68 \mathrm{~kg}$, BMI: $23.03 \pm 1.71 \mathrm{~kg} / \mathrm{m}^{2}$, and exercise history: $5.25 \pm 1.60$ years). The experimental group performed a 6 -week training program, 3 sessions per week, each session consisting of 40 minutes of core stabilization exercises and hopping. A questionnaire was used to collect demographic information and exercise history, and the Y-balance test and stork stand balance test were used to measure static and dynamic equilibrium, respectively. In addition, the strength of the core part was evaluated by trunk $60^{\circ}$ flexion, Biering-Sorensen, forearm plank, and side plank (right and left) tests. The Shapiro-Wilk test was used to check the normality of the data. In the case of normal data, the paired t-test was used to evaluate the differences in mean values.

Results: The results of this study showed a significant difference between the mean posttest scores of trunk strength and static and dynamic balance in both experimental and control groups $(\mathrm{P}<0.001)$ so that the subjects in the experimental group performed better in these tests. All statistical tests were performed at a significance level of $95 \%(\mathrm{P}<0.05)$.

Conclusion: The results of the present study show that combined balancing exercises for the core part of the body and hopping can improve the balance and endurance of the Kabaddi athletes and, thus, may prevent potential injuries.

\section{* Corresponding Author:}




\section{Highlights}

- In this study, static balance was measured using the stork test.

- In this study, dynamic balance is the score that the subject obtains from the Y-balance test.

- In this study, core stability exercises as well as hopping exercises were performed for 6 weeks.

\section{Plain Language Summary}

Two groups, experimental and control, consist of 24 female Kabaddi players were selected. The experimental group performed a 6-week training program of core stabilization exercises and hopping. A questionnaire was used to collect information and exercise history. The strength of the core part was evaluated by trunk $60^{\circ}$ flexion, Biering-Sorensen, forearm plank, and side plank tests. The Shapiro-Wilk test was used to check the normality of the data. In the case of normal data, the paired $\mathrm{t}$-test was used to evaluate the differences in mean values. The results showed a significant difference between the mean posttest scores of trunk strength and static and dynamic balance in both experimental and control groups so that the subjects in the experimental group performed better in these tests. All statistical tests were performed at a significance level. The results show that combined balancing exercises for the core part of the body and hopping can improve the balance and endurance of the Kabaddi athletes and, thus, may prevent potential injuries.

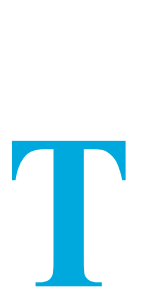

\section{Introduction}

oday, because of industrial advancement and the mechanization of life, people have less physical activity. One of the problems associated with impaired mobility and exercise is an imbalance or poor balance of movement. In recent years, for many people, the core part of the body and the exercises related to its strengthening and stability has become considerably important in different areas. The waist, hip, and thigh, along with their surrounding muscles, are considered as the core parts of the body. Regarding this anatomical position, the center of gravity is located in this area and the movements and transmission of force from the upper extremity to the lower extremity and vice versa, as the integral chain of motion of the human body, mainly result from this region; therefore, its stability is extremely important [1].

The core part of the body is considered as a muscular box, with the muscles of the abdomen in the front, the muscles around the spinal column and the gluteus maximus gait on the back, the diaphragm on the roof, and the pelvic floor muscles and the pelvic belt in the floor. These muscles contribute to the stability of the spine, the hip, and the chain of functional movements [2]. The weakness or lack of coordination in the muscular structure of the core part of the body can reduce the effect of correct movement patterns or may cause the occurrence of compensatory motor patterns, muscle tension, hyperfunction, and, ultimately, injuries [3]. Therefore, it seems that the first step in developing a stable core part lies in the development of the strength and endurance of the lumbar-pelvic muscles.

The central muscles act as a bridge between the upper and lower extremities, in which the force is produced from the core part and transmitted to the organs. Initially, stability requires maintaining a neutral status in the spinal column; however, there must be a situation where the spine is no more neutral [4]. Increasing the strength and endurance of the core part can play an important role in improving efficiency [5]. The coordinated and proper functioning of the muscles of the body is essential for the production, transfer, and proper control of the forces and movements that occur in the body. The coordinated activation of the central muscle is essential for the stability and efficacy of functioning, which involves controlling the strength, balance, and movement of the core part of the body [6].

Experts believe that even if the upper and lower extremities are strong while the central muscles are weak, the reduction of muscle accumulation forces in the central muscles of the trunk decreases the overall force production in the upper and lower extremities, which in turn prevents the effective movements [6]. The disruption of trunk muscle control and muscular instability ultimately leads to imbalance, poor physical fitness, pain, and injury. The control of the condition and body status has two dimensions: static and dynamic. The static dimension is 
when body tries to maintain a level of reliance with the least amount of movement. The dynamic dimension is when body tries to maintain a level of reliance when performing various motions [7].

Today, much attention is paid to the high level of balance and a deep sense of mindfulness toward the athletes' rehabilitation. It is hypothesized that after the injury, the sensory-bodily signals reduce and the neuromuscular control is interrupted. If static and dynamic balance and neuromuscular control do not improve in a person, he or she is susceptible to injury and will be in trouble in his or her athletic performance [8].

The hopping exercise program is one of the plyometric training programs used to improve balance. It is a modified and relatively adjusted plyometric exercise characterized by a stretch-shortening cycle and is used to measure the quality of the level of athlete's performance by stimulating the muscles and the pressure on the joint during sports and exercises $[9,10]$. Power and balance are two essential components of hopping [11]. Researchers have argued that hopping exercises create a link between power and coordination and directly enhance positive performance during competition, leading to the athletes' success in various sport branches [12].

Kabaddi is a traditional sport in India, which has recently spread in most parts of Asia, such as Iran. It requires high physical strength, agility, individual skill, neuromuscular coordination, high aerobic endurance, and rapid and smarty reactions $[13,14]$. Kabaddi players, the same as other athletes of different kinds of sports, perform long-term exercises that cause fatigue in various parts of the muscle control structures, including the central nervous system, nervous muscle control, and muscle itself, which reduces muscle performance and increases the risk of post-fatigue damage [14].

Injuries may occur as a result of a simple accident or a complex interaction of internal and external risk factors. Internal risk factors include the internal characteristics of the athlete that cause injuries or potentially increase the risk of injury. For example, age, sex, weight, previous injury, aerobic fitness, superior organ, flexibility, muscle strength, and sex hormones can be mentioned. External risk factors are related to the environment and sports facilities, which include the level of competition, skill level, type of shoe, ankle brace, climate change, and playground quality. Another pathological aspect is to identify the exercises, which may result in injuries [15].
Research conducted in Scandinavia shows that sports injuries account for about $10 \%$ to $19 \%$ of acute injuries in hospital emergency wards, and the most common ones are knee injuries, which along with ankle injury, are recognized as the most vulnerable area in Kabaddi exercises $[14,16]$. According to one of the reports, the highest prevalence of knee and ankle injuries are related to sports that have shear and jerk movements [17]. These injuries not only endanger the athlete's health but also reduce his or her physical fitness and the loss of exercise time [18]. On the other hand, some studies emphasize the relationship between physical fitness and core stabilization performance, which its disregard can cause injury [10].

Given this, exercise is used as an intervention to improve balance and endurance among athletes. Assuming the effectiveness of hopping and core stabilization exercises on endurance to reduce the risk of injury, the present study examines the effects of combined stability training and hopping on trunk endurance and balance in female Kabaddi athletes.

Exercises related to core stabilization part, while maintaining the relationship between normal long-standing tensions in the main muscles of both sides, will stabilize and strengthen the muscle in the core part, which in turn results in the creation of a pair of natural forces for maintaining the lumbar-pelvic-femoral structure. The rehabilitation of the upper limb and lower back pain include neuromuscular and core stabilization nervous system training. Although following the lower limb injuries, neuromuscular exercises have been extensively studied in clinical trials, and there are still some contradictions in the use of core stabilization exercises for the treatment of lower limb injuries [19]. On the other hand, since strength and balance are two essential components of hopping, it may be effective when combining with core part exercises to improve endurance and balance and reduce the risk of injury [11].

Since in the Kabaddi exercises, the same as wrestling, there are great clashes, shears, and rapid movements among the players, (which characterize it as a strong and fast-moving sport with quick horizontal and vertical movements of the athlete's body) that require a lot of energy, it seems that these athletes are more prone to injuries. On the other hand, in this sport, the nature of individual defense and individual and group faults during the game makes the players prone to various types of injuries $[14,20]$. In other words, the combination of technical and tactical strategies and highly physical fitness has introduced this sport, like some other sports, as 
a high-impact sport. Therefore, attention should be paid to the implementation of injury prevention programs for Kabaddi players [14].

Regarding the fact that Kabaddi is a highly active sport with explosive movements, in which trunk area has an important role in rapid transfer of strength and proper function in the prevention of the risk of injury, it seems that the combination of these two exercises (hopping and trunk core exercises) can greatly improve the endurance and balance of these athletes. No study has yet examined the effectiveness of the combination of hopping and core trunk stabilization on endurance and balance simultaneously in the Kabaddi players (although both are considered as important variables in physical fitness). To the best of the researcher's knowledge, no studies have been found to evaluate the factors and exercises affecting these athletes; hence, this study aimed at assessing the effects of this exercise protocol on the improvement of the probable trunk endurance and balance of these athletes.

\section{Materials and Methods}

The present study is quasi-experimental applied research. The statistical population of the study was all female Kabaddi athletes. According to the pilot study, considering the statistical methods, reference articles, and using the "G power" software (taking into account that $r^{2}=0.50$, power $=0.80$ and $\alpha=0.05$ ), the sample size for the present study was estimated 24 people. They were selected by random sampling method and divided into control (12 subjects) and experimental (12 people) groups (Table 1). The inclusion criteria included being Kabaddi athletes with at least 3 years of experience in this field, being female, and participating voluntarily. It is worth noting that the subjects with acute head, spine, pelvis, thighs, knees, and ankles injuries and other injuries that could affect the balance of the person were excluded from the research according to the registration form.

The subjects were selected from the women's sports clubs in Golestan Province, Iran. After receiving consent from the coach and supervisor of the teams, and also distributing the questionnaire, the subjects, who wanted to participate in the research, were selected and briefed with the subjects' conditions. They were also informed about the items, which may prevent them from entering into the study and research process. After they filled the application and consent form and expressed their consent, the evaluation began. Then, the anthropometric measurements were done. The height of the subjects was measured by a stretchable measuring tape, and the weight was measured by a scale (BPS-9370 model). Afterward, the subjects were divided into two groups to perform the core stabilization tests. These tests included a flexor torsion endurance test (flexure-torsion at $60^{\circ}$ ), an extensor endurance test (Bearing-Sorensen), side plank test (left and right), and front plank test. The average time of field tests for core trunk stabilization tests was approximately 40 minutes for each person.

The torsional flexor endurance test was performed to evaluate the functional endurance of the anterior core muscles, especially the right side abdominal muscles. The test started as the subjects leaned back to a board with a $60^{\circ}$ angle, bending both hip and knee with a $90^{\circ}$ angle and crossed arms on chest. An assistant helped them to fix their ankles. To start the test, the board moved away $10 \mathrm{~cm}$ from the back of the subjects, while they were leaning against it and were asked to maintain this position as long as possible. As soon as they contacted the bed, the experiment ended [2].

The trunk extensor endurance test was performed to measure the posterior core muscles of the body (especially the erector spinae or spinal erectors), which is called the Bearing-Sorenson test. The subjects were asked to lie face down on the stomach so that their pelvic bones were placed at the edge of the bed. An assistant helped them protect and maintain their stability. The upper part of the subject was kept horizontally, holding the arms in chest cross-cut. The duration of maintaining this condition was recorded as the trunk extensor endurance [2]

The side plank test is considered as an assessment of the lateral muscles of the core body part, especially the lumbar square segment. The subject was asked to lie on a lateral position, with the upper leg in front of the lower leg, and the hip joints with no flexion. The subject was, then, asked to lift the thighs from the bed and use his or her legs and elbows to support and maintain the position. In this test, the free arm should be placed on the shoulder of the opposite side [2].

To perform a front plank, while lied face down on the stomach and trying to maintain the core part in a neutral position, the subjects supported the body by the arms and toes and tried to resume this position. The body in this test must be in the same direction. The test was stopped when the body got out of balance (excessive curvature in the spine) [2].

Subsequently, in the second session and the second day, the stork balance test and Y-balance test were performed to assess the static and dynamic balance in the subjects' 
Table 1. Overview of the research

\begin{tabular}{cccc}
\hline Group & Pre-test & Intervention & Post-test \\
\hline Experimental & $\mathrm{T} 1$ & Selected core trunk stabilization and hopping exercises & T2 \\
Control & $\mathrm{T} 1$ & $\mathrm{~T} 2$ \\
\hline
\end{tabular}

PHYSICAL TREA $\$ MENTS

body in both groups. The stork balance test was used to evaluate the static balance. In this test, the subject stands on the dominant foot, and with the hands-on waist, he or she holds the other leg's toes on the knee of the standing leg. Then, the subject by the command "present!" and, then, by the command "Go!" raises the heel of the dominant foot, and while standing on the toes, he or she tries to maintain his or her balance with the leg still immobile and hands on the waist. The test was run 3 times, and the best time was recorded as the score of the test [21].

To evaluate the dynamic balance, the modified Y-balance test was used. The test was performed in such a way that, first, the researchers announced the starting time, but before that, they repeatedly did some warm-up exercises. Then, in the main test, the subjects stood on one leg at the center of the intersection of the lines, and at the same time they were asked to access to their free leg in the anterior, posterior, and lateral posterior directions in such a way that the subject stood on his or her right leg and started to access in the anterior direction 3 times. Finally, they stood on the left foot and repeated the action in the same direction 3 times. This procedure was also repeated on the posterior and lateral posterior.

The length of the legs in this test affected the mean distance of their access; thus, to normalize it, the mean distance of their access was divided into the length of the legs of each subject and multiplied by 100 to calculate the dependent variable and the distance of access as a percentage of the foot length [2]. Then, the experimental group performed the core trunk stabilization and hopping tests for 6 weeks. At the end of the training program, the subjects began the posttest again. During this interval, the control group was asked to stop strength and balance exercises.

The obtained data were processed in SPSS V. 23. Descriptive statistics were used to present the central tendency and dispersion characteristics. To test the normality of the data, the Shapiro-Wilk test was used, and to compare the pretest and posttest data in each group, $\mathrm{t}$-test correlation was used. All statistical tests were calculated at a significance level of $95 \%(\mathrm{P}<0.05)$.

Table 2. Selected training protocol for core trunk stabilization and hopping exercises

\begin{tabular}{|c|c|c|}
\hline Week & Practice & Set, Repeat, Time \\
\hline \multirow{7}{*}{ The first week } & Hopping to the sides on two legs (hands-free) & $3 \times 10$ repetitions \\
\hline & Hopping to front and back on two legs (hands-free) & $2 \times 10$ repetitions \\
\hline & Hopping to the front on two legs (hands-free) & $2 \times 10$ repetitions \\
\hline & Pulled abdominal muscle & $3 \times 20 s$ \\
\hline & Bridging in face-down position & $3 \times 20 s$ \\
\hline & Bridging in the supine position & $3 \times 20 s$ \\
\hline & Side bridging (right and left) & $3 \times 20 s$ \\
\hline \multirow{9}{*}{ The second week } & Hopping to the sides on two legs (hands on the chest) & $2 \times 15$ repetitions \\
\hline & Hopping to front and back on two legs (hands-free) & $2 \times 10$ repetitions \\
\hline & Hopping to the front on two legs (hands-free) & $2 \times 10$ repetitions \\
\hline & Hopping to the sides on one leg (hands-free) & $5 \times 4$ repetitions \\
\hline & Lifting the leg in a supine position on a knee bent & $3 \times 20$ repetitions \\
\hline & Rising the opposite hand and foot in quadriceps & $3 \times 20$ repetitions \\
\hline & Bridging in supine position along with opening the left and right legs alternately & $3 \times 20$ repetitions \\
\hline & Sitting on a physioball and walking in place & $3 \times 20$ repetitions \\
\hline & Cross crunch abdominal muscles & $3 \times 20$ repetitions \\
\hline
\end{tabular}




\begin{tabular}{|c|c|c|}
\hline Week & Practice & Set, Repeat, Time \\
\hline \multirow{9}{*}{ The third week } & Hopping to the sides on one leg (hands on the chest) & $3 \times 10$ repetitions \\
\hline & Hopping to front and back on one leg (hands-free) & $2 \times 10$ repetitions \\
\hline & Hopping to the front on two legs (hands on the chest) & $3 \times 10$ repetitions \\
\hline & Hopping zig-zag on two legs (hands-free) & $2 \times 10$ repetitions \\
\hline & Bridging in a supine position on a physioball & $3 \times 20$ repetitions \\
\hline & Bridging in a supine position on physioball along with shoulder shrug & $3 \times 20$ repetitions \\
\hline & Bridging in face-down position on a physioball & $3 \times 20$ repetitions \\
\hline & Cobra exercise on a physioball & $3 \times 20$ repetitions \\
\hline & Superman exercise & $3 \times 20$ repetitions with stopping of $2 \mathrm{~s}$ \\
\hline \multirow{10}{*}{ The fourth week } & Hopping to the sides on one leg (hands on the chest) & $2 \times 10$ repetitions \\
\hline & Hopping to front and back on one leg (hands on the chest) & $2 \times 10$ repetitions \\
\hline & Hopping to the front on two legs (hands-free) & $3 \times 10$ repetitions \\
\hline & Hopping zig-zag on one leg (hands-free) & $2 \times 10$ repetitions \\
\hline & Hopping through squares on two legs (hands-free) & $2 \times 10$ repetitions \\
\hline & Rotating the trunk in a sitting position by taking physioball in hands & $3 \times 20$ repetitions \\
\hline & Bridging the pelvis on a physioball with shoulder bent & $3 \times 20$ repetitions \\
\hline & Sit-up on a physioball & $3 \times 20$ repetitions \\
\hline & $\begin{array}{c}\text { Bridging the pelvis on a physioball with opening the knees alternately with shoulder } \\
\text { bent }\end{array}$ & $3 \times 20$ repetitions \\
\hline & Superman exercise on a physioball & $3 \times 20$ repetitions with stopping of $2 \mathrm{~s}$ \\
\hline \multirow{10}{*}{ The fifth week } & Hopping to the sides on one leg (hands behind) & $2 \times 10$ repetitions \\
\hline & Hopping to front and back on one leg (hands behind) & $2 \times 10$ repetitions \\
\hline & Hopping to the front on one leg (hands on the chest) & $2 \times 10$ repetitions \\
\hline & Hopping zig-zag on one leg (hands on the chest) & $2 \times 10$ repetitions \\
\hline & Hopping through squares on one leg (hands-free) & $2 \times 10$ repetitions \\
\hline & Hopping in 8-shape on two legs (hands-free) & $2 \times 10$ repetitions \\
\hline & Lunge exercise by rotating the trunk with a medicine ball in hand & $3 \times 20$ repetitions \\
\hline & Bending the trunk with medicine ball wings on a physioball & $3 \times 20$ repetitions \\
\hline & Swaying a physioball forward and backward & $3 \times 20$ repetitions with stopping of $2 \mathrm{~s}$ \\
\hline & Bridging on a physioball and putting and raising legs on the ball alternately & $3 \times 10$ repetitions on each leg \\
\hline \multirow{10}{*}{ The sixth week } & Hopping to the sides on one leg (hands behind) & $3 \times 10$ repetitions \\
\hline & Hopping to front and back on one leg (hands behind) & $2 \times 10$ repetitions \\
\hline & Hopping to the front on one leg (hands behind) & $2 \times 10$ repetitions \\
\hline & Hopping zig-zag on one leg (hands behind) & $2 \times 10$ repetitions \\
\hline & Hopping through squares on one leg (hands on the chest) & $2 \times 10$ repetitions \\
\hline & Hopping in 8-shape on one leg (hands-free) & $2 \times 10$ repetitions \\
\hline & Lunge exercise with putting back leg on a physioball & $3 \times 10$ repetitions on each leg \\
\hline & March exercise along with stretching exercises & $3 \times 10$ repetitions on each leg \\
\hline & Bridging the pelvis along with backing the shoulder & $3 \times 15$ repetitions on each side \\
\hline & Superman exercise on physioball alternately & $3 \times 10$ repetitions \\
\hline
\end{tabular}

\section{Moral considerations}

At the beginning of the study, all subjects completed the consent form of the research. The subjects were fully acquainted with the protocol. Moreover, each subject, if desired, could discontinue the research at any phase of the research.

\section{Practice protocol}

The experimental group performed a selected combined training program of core trunk stabilization and hopping for six weeks and three sessions per week, and each session 1 hour (Table 2). The exercises increased in intensity after the end of each week. This training pro- 
Table 3. Personal information of the subjects (12 subjects)

\begin{tabular}{ccc}
\hline & & Mean \pm SD \\
Variables & Experimental Group & Control Group \\
\cline { 2 - 3 } & $16.83 \pm 1.26$ & $16.42 \pm 0.99$ \\
\hline Age $(\mathrm{y})$ & $1.61 \pm 0.04$ & $1.60 \pm 0.05$ \\
\hline Height $(\mathrm{m})$ & $56.50 \pm 3.06$ & $59.08 \pm 8.68$ \\
\hline Weight $(\mathrm{kg})$ & $21.84 \pm 1.73$ & $23.03 \pm 1.71$ \\
\hline BMl $\left(\mathrm{kg} / \mathrm{m}^{2}\right)$ & $5.08 \pm 1.08$ & $5.25 \pm 1.60$ \\
\hline Sports history $(\mathrm{y})$ & & PHYSICAL TREATMENTS
\end{tabular}

Table 4. The difference in Mean \pm SD scores of the test of subjects' trunk endurance in both groups $(n=12)$

\begin{tabular}{|c|c|c|c|c|c|c|c|c|}
\hline \multirow{3}{*}{ Groups } & \multicolumn{4}{|c|}{ Experimental } & \multicolumn{4}{|c|}{ Control } \\
\hline & \multicolumn{2}{|c|}{ Mean $\pm S D$} & \multirow{2}{*}{$\mathbf{T}$} & \multirow{2}{*}{$\mathbf{P}^{*}$} & \multicolumn{2}{|c|}{ Mean $\pm S D$} & \multirow{2}{*}{$\mathbf{T}$} & \multirow{2}{*}{$\mathbf{P}$} \\
\hline & Pre-test & Post-test & & & Pre-test & Post-test & & \\
\hline Flexion of $60^{\circ}$ & $75.50 \pm 6.94$ & $83.75 \pm 7.65$ & -4.58 & 0.001 & $73.75 \pm 2.00$ & $76.41 \pm 7.65$ & -1.48 & 0.16 \\
\hline Sorensen & $67.91 \pm 3.23$ & $77.08 \pm 5.93$ & -6.08 & 0.01 & $68.91 \pm 3.67$ & $70.58 \pm 4.35$ & -1.16 & 0.28 \\
\hline Abdominal plank & $63.50 \pm 2.81$ & $73.75 \pm 5.64$ & -6.56 & 0.001 & $64.25 \pm 3.88$ & $65.91 \pm 4.35$ & -1.08 & 0.30 \\
\hline Right plank & $64.08 \pm 2.99$ & $70.25 \pm 5.11$ & -4.25 & 0.001 & $63.50 \pm 6.24$ & $63.66 \pm 6.94$ & -0.19 & 0.58 \\
\hline Left plank & $65.00 \pm 4.36$ & $77.66 \pm 5.64$ & -6.25 & 0.001 & $63.33 \pm 4.03$ & $66.58 \pm 4.92$ & -0.19 & 0.85 \\
\hline
\end{tabular}

* Indicates statically significant difference

PHYSICAL TREATMENTS

gram was based on the study of Abbasi et al. approved by the practitioners and experts [22].

\section{Results}

Table 3 presents the descriptive statistics of the personal information of the subjects in both experimental (combined training of core trunk stabilization and hopping groups) and control groups.
Regarding the natural distribution of data and the number of variables, t-test correlation was used to examine the pretest and posttest data of these variables.

In Table 4, the results of the t-test correlation were presented to evaluate the mean scores of trunk endurance tests in subjects before and after the practice protocol. According to the test statistic, there was a significant difference between the scores of the trunk endurance tests of Kabaddi players in the experimental group before and after the practice protocol.

Table 5. The difference in Mean \pm SD scores of the test of subjects' static balance in both groups $(n=12)$

\begin{tabular}{|c|c|c|c|c|c|c|c|c|}
\hline \multirow{3}{*}{ Group } & \multicolumn{4}{|c|}{ Experimental } & \multicolumn{4}{|c|}{ Control } \\
\hline & \multicolumn{2}{|c|}{ Mean \pm SD } & \multirow{2}{*}{$\mathbf{T}$} & \multirow{2}{*}{$\mathbf{P}^{*}$} & \multicolumn{2}{|c|}{ Mean \pm SD } & \multirow{2}{*}{$\mathbf{T}$} & \multirow{2}{*}{$\mathbf{P}$} \\
\hline & Pre-test & Post-test & & & Pre-test & Post-test & & \\
\hline Stork balance & $9.33 \pm 1.85$ & $15.18 \pm 2.64$ & -8.08 & 0.001 & $10.07 \pm 2.24$ & $10.72 \pm 2.34$ & -0.51 & 0.15 \\
\hline
\end{tabular}

* Indicates statically significant difference 
Table 6. The difference in the Mean \pm SD scores of the test of subjects' dynamic balance in both groups $(n=12)$

\begin{tabular}{|c|c|c|c|c|c|c|c|c|}
\hline \multirow{3}{*}{ Groups } & \multicolumn{4}{|c|}{ Experimental } & \multicolumn{4}{|c|}{ Control } \\
\hline & \multicolumn{2}{|c|}{ Mean \pm SD } & \multirow{2}{*}{$\mathbf{T}$} & \multirow{2}{*}{$\mathbf{P}$} & \multicolumn{2}{|c|}{ Mean \pm SD } & \multirow{2}{*}{$\mathbf{T}$} & \multirow{2}{*}{$\mathbf{P}$} \\
\hline & Pre-test & Post-test & & & Pre-test & Post-test & & \\
\hline Anterior direction & $82.35 \pm 6.18$ & $88.56 \pm 5.21$ & -12.22 & $* 0.001$ & $82.41 \pm 6.30$ & $82.85 \pm 5.96$ & -0.52 & 0.60 \\
\hline Internal posterior direction & $87.42 \pm 6.63$ & $95.71 \pm 4.21$ & -7.02 & $* 0.001$ & $86.59 \pm 4.37$ & $89.36 \pm 3.32$ & -1.73 & 0.11 \\
\hline External posterior direction & $82.54 \pm 4.33$ & $89.69 \pm 4.01$ & -6.61 & $* 0.001$ & $82.83 \pm 9.44$ & $65.91 \pm 4.35$ & -1.35 & 0.20 \\
\hline Total & $84.10 \pm 3.19$ & $91.32 \pm 2.33$ & -13.89 & $* 0.001$ & $83.23 \pm 4.90$ & $85.01 \pm 4.90$ & -1.76 & 0.10 \\
\hline
\end{tabular}

* Indicates statically significant difference.

In Table 5, the results of the t-test correlation were presented to evaluate the mean scores of static balance tests in subjects before and after the practice protocol. According to the test statistic, there was a significant difference between the scores of the static balance tests of Kabaddi players in the experimental group before and after the practice protocol.

According to the results of Table 5, there was a significant difference between the mean posttest scores of static balance in both experimental and control groups; the experimental group performed better in the static balance test.

In Table 6, the results of the t-test correlation were presented to evaluate the mean scores of dynamic balance tests in subjects before and after the practice protocol. According to the test statistic, there was a significant difference between the scores of the dynamic balance tests of Kabaddi players in the experimental group before and after the practice protocol.

According to the results of Table 6, there was a significant difference between the mean posttest scores of dynamic balance in both experimental and control groups; the experimental group performed better in dynamic balance test.

\section{Discussion}

The results of t-test correlation showed that the six week combined exercises of core trunk stabilization and hopping had a significant effect on the results of all the muscular endurance tests of the core body part of the subjects. The results of this study were consistent with the results of studies by Haddadnezhad et al. and Faiz et al. [23, 24].
Based on the results of previous studies on core stabilization, it seems that facilitating the simultaneous muscle contractions around the lumbar spines, such as transverse abdominal muscle, abdominal oblique muscle, multifidus, and vertebral column outright may increase the stability of the vertebrae [25]. Hence, the goal of core stabilization exercises is to create a physical capacity to maintain a neutral position in the vertebrae during daily activities, which is done by increasing the tolerance and coordination of vertebrate stabilizing muscles [26].

Faiz et al. pointed out the importance and influence of Swiss ball exercises on the improvement of trunk strength, followed by the endurance of the core part [24]. The larger muscles of the core part of the body create a stable level of motion for the body by providing a solid cylinder and, subsequently, producing more inertia against body turbidity. Abdominal muscles, including the transverse abdominal, right abdomen, internal diagonal, and external diagonal are all integrated to provide spine stability and, subsequently, a stronger reliance on lower limb movements [27]. When the transverse abdominal muscles contract, the internal diagonal muscle pressure increases and causes the lumbar spine to tension. These contractions occur before the movement of the organs to allow the organs to have a stable level of muscle movement and activation. On the other hand, the right abdominal muscles and abdominal diagonal muscles are also active in specific patterns relative to the movement of the organs that provide support for the vertebral column [27].

The role of trunk stabilizers is to maintain muscle function system, control, coordination, and ideal performance. Lower abdominal muscles of the trunk cause trunk fatigue during intense exercise or tournaments with less coordination between the lower and upper 
extremities and may also reduce muscle strength. It is argued that if the ratio of strength to trunk muscle endurance is greater than 4 , this is likely to be a problem for the lower back area [28].

Muscular endurance is an essential element in demonstrating the level of physical fitness and the normal functionality of the structure of the human body. Hence, reducing the endurance of muscle groups may cause abnormal movement or displacement in different parts of the body, which motivated many researchers to study the role of trunk muscles in protecting the spine from harmful stress. The muscles around the spine are postural muscles that help keep your body straight when standing and control your body when bending and straightening.

According to a theory, any decrease of the trunk muscle endurance causes muscle fatigue and increases pressure on soft tissues and other inactive structures of the lumbar spine. Also, since muscle endurance capacity is a sign of their fatigue capacity, people with lower trunk muscle endurance are more supposed to be exposed to structural pressures, which may lead to inappropriate pressure on the spinal column and cause lower back pain [29]. Thus, the core stabilization exercises can be important in preventing and rehabilitating spinal problems and improving performance, considering their effectiveness in improving trunk muscle endurance.

Many types of research have shown that there is probably no other area of the body as important as the core body to be considered. If the lumbar spine has a back and hip joint pain, it shows that the person needs to have stabilization exercises. Studies in this regard pointed to the positive effect of core stabilization exercises on pain relief [30, 31]. It seems that the improvement of endurance in the present study is related to the nature and difficulty of the exercises, as well as the use of functional exercises since using core stabilization exercises related to functional exercises of the field of sport can affect the good performance of the person and bring about improvements.

The results also showed that the core stabilization exercises along with hopping had positive effects on the subjects' static and dynamic balance so that, according to the statistical results, the improvement in the static and dynamic balance of the subjects in 3 directions, as well as the general balance index, occurred.

The results of this study were consistent with the findings of studies by McCaskey, Carpes et al. Mills et al. Filipa et al. and Gordon et al. all of which reported im- provement in balance after applying the different programs of core body exercises [32-36]. The probable cause of the increase in balance can be attributed to the improvement in strength and endurance characteristics of the core region of the body, which was also shown in this study.

The Star Excursion Balance Test (SEBT), or in this study the Y-balance test, requires neuromuscular control for the proper position of the joint and the strength of the muscle-building around the joint during the test [37]. Olmstedt et al. found that reliance on the ankle flexion, knee flexion, and femoral flexion required a jump to dorsiflexion during the test. Therefore, the lower extremity requires an appropriate range of motion, strength, deep receptor activity, and neuromuscular control [38]. Earl et al. showed that SEBT is directly dependent on the activity of lower limb muscles, except for twin muscle [39].

During the SEBT access in all directions, hamstring and quadriceps muscle contraction occur. The quadriceps has the most activity in the 3 directions of anterior, posterior, and lateral posterior; because for doing these anterior directions movements, the participants should rely on the rear and trunk in the extended position to maintain their balance. In this position, the gravitational force acting on the upper part causes a high torque of the knee flexion to be controlled by the extension torque (eccentric contractions) produced by the quadriceps muscle [40]. The most activity belongs to the outer broad-band muscle in the anterior and lateral posterior side, which is likely to be owing to muscle fixation that occurs against the active muscular forces within these directions. Based on these findings, it may be concluded that increasing power and eccentric control of quadriceps muscles can improve balance control in these directions and show the improvement of injury in different stages [35, 39].

During the performance of the SEBT-test, the bicipital muscle is also active and has the most activity in the directions of anterior, posterior, and lateral posterior. This phenomenon can be justified by the effect of the gravitational force acting on the trunk, which causes the thigh flexion torque [39]. To perform posterior directions actions, the person must have a flexion trunk to open the leg backward; in this position, the hamstring muscles must be contracted outward to resist the thigh flexion torque. Moreover, performing the test outwardly has a dire need for severe thigh outward turning; thus, it results in a high activity of the biceps muscle [39].

According to the discussion, the strength of the surrounding and operating muscles on joint and their co- 
contraction to stable the relying lower limb joints, the proper range of motion, the deep receptor activity, and neuromuscular control to maintain balance while accessing and obtaining the greatest distance are of particular importance, which are also important in the results of the static balance test. On the other hand, functional and dynamic exercises in the training program have been effective in improving the dynamic balance of these athletes.

\section{Ethical Considerations}

\section{Compliance with ethical guidelines}

All ethical principles were considered in this article.

Funding

This research did not receive any specific grant from funding agencies in the public, commercial, or not-forprofit sectors.

\section{Authors' contributions}

All authors contributed in preparing this article.

\section{Conflict of interest}

The authors declared no conflict of interest.

\section{Refrences}

[1] Kibler WB, Press J, Sciascia A. The role of core stability in athletic function. Sports Medicine. 2006; 36(3):189-98. [DOI:10.2165/00007256-200636030-00001] [PMID]

[2] Reed CA, Ford KR, Myer GD, Hewett TE. The effects of isolated and integrated 'core stability' training on athletic performance measures: A systematic review. Sports Medicine. 2012; 42(8):697-706. [DOI:10.1007/BF03262289] [PMID]

[3] Sharrock C, Cropper J, Mostad J, Johnson M, Malone T. A pilot study of core stability and athletic performance: Is there a relationship? International Journal of Sports Physical Therapy. 2011. 6(2):63-74. [PMID] [PMCID]

[4] Granacher U, Lacroix A, Muehlbauer T, Roettger K, Gollhofer A. Effects of core instability strength training on trunk muscle strength, spinal mobility, dynamic balance and functional mobility in older adults. Gerontology. 2013; 59(2):10513. [DOI:10.1159/000343152] [PMID]

[5] Sekendiz B, Cuğ M, Korkusuz F. Effects of Swiss-ball core strength training on strength, endurance, flexibility, and balance in sedentary women. Journal of Strength \& Conditioning Research. 2010; 24(11):3032-40. [DOI:10.1519/ JSC.0b013e3181d82e70] [PMID]
[6] Dello Iacono A, Padulo J, Ayalon M. Core stability training on lower limb balance strength. Journal of Sports Sciences. 2016; 34(7):671-8. [DOI:10.1080/02640414.2015.1068437] [PMID]

[7] Chimera NJ, Smith CA, Warren M. Injury history, sex, and performance on the functional movement screen and $\mathrm{Y}$ balance test. Journal of Athletic Training. 2015; 50(5):475-85. [DOI:10.4085/1062-6050-49.6.02] [PMID] [PMCID]

[8] Wright AA, Dischiavi SL, Smoliga JM, Taylor JB, Hegedus EJ. Association of Lower Quarter Y-Balance Test with lower extremity injury in NCAA division 1 athletes: An independent validation study. Physiotherapy. 2017; 103(2):231-6. [DOI:10.1016/j.physio.2016.06.002] [PMID]

[9] Tveter AT, Holm I. Influence of thigh muscle strength and balance on hop length in one-legged hopping in children aged 7-12 years. Gait \& Posture. 2010; 32(2):259-62. [DOI:10.1016/j.gaitpost.2010.05.009] [PMID]

[10] Buchanan AS, Docherty CL, Schrader J. Functional performance testing in participants with functional ankle instability and in a healthy control group. Journal of Athletic Training. 2008; 43(4):342-6. [DOI:10.4085/1062-6050-43.4.342] [PMID] [PMCID]

[11] Holm I, Tveter AT, Fredriksen PM, Vøllestad N. A normative sample of gait and hopping on one leg parameters in children 7-12 years of age. Gait \& Posture. 2009; 29(2):317-21. [DOI:10.1016/j.gaitpost.2008.09.016] [PMID]

[12] Huang P, Lin C. Effects of balance training combined with plyometric exercise in postural control: Application in individuals with functional ankle instability. Paper presented at: 6th World Congress of Biomechanics (WCB 2010). 1-6 August 2010. Singapore, Singapore.

[13] Dhillon, M.S., et al., Epidemiology of knee injuries in Indian Kabaddi players. Asian Journal of Sports Medicine, 2017. 8(1). [DOI:10.5812/asjsm.31670]

[14] Murthy V. Common injuries in kabaddi play and their prevention with the help of biomechanics. International Journal of Physical Education, Sports and Health. 2016; 3(4):78-81.

[15] Hägglund M, Waldén M, Ekstrand J. Risk factors for lower extremity muscle injury in professional soccer: the UEFA Injury Study. American Journal of Sports Medicine. 2013; 41(2):327-35. [DOI:10.1177/0363546512470634] [PMID]

[16] Bahr R, Krosshaug T. Understanding injury mechanisms: a key component of preventing injuries in sport. British Journal of Sports Medicine. 2005; 39(6):324-9. [DOI:10.1136/ bjsm.2005.018341] [PMID] [PMCID]

[17] Brown C, Bowser B, Simpson KJ. Movement variability during single leg jump landings in individuals with and without chronic ankle instability. Clinical Biomechanics. 2012; 27(1):52-63. [DOI:10.1016/j.clinbiomech.2011.07.012] [PMID]

[18] Kaufman KR, Brodine S, Shaffer R. Military trainingrelated injuries: Surveillance, research, and prevention. American Journal of Preventive Medicine. 2000; 18(3):54-63. [DOI:10.1016/S0749-3797(00)00114-8]

[19] Piegaro A. The comparative effects of four-week core stabilization and balance-training programs on semidynamic and dynamic balance [MSc. Thesis]. Morgantown. WV: West Virginia University; 2003. 
[20] Langevoort G, Myklebust G, Dvorak J, Junge A. Handball injuries during major international tournaments. Scandinavian Journal of Medicine \& Science in Sports. 2007; 17(4):4007. [DOI:10.1111/j.1600-0838.2006.00587.x] [PMID]

[21] Reiman MP, Manske RC. Functional testing in human performance, $1^{\text {st }}$ edition. Champaign, IL: Human kinetics; 2009.

[22] Abbasi H, Alizadeh MH, Daneshmandi H, Barati AH [Comparing the effect of functional, extra-functional and combined exercises on dynamic balance in athletes with functional ankle instability (Persian)]. Sport Sciences Research Institute. 2015; 7(17):15-34.

[23] Hadadnezhad, M., Et Al., Effect of stabilization training on trunk muscle activation of females with trunk control deficit (Persian)]. Sport Sciences Research Institute. 2015; 7(17): 51-68.

[24] Faiz A, Gnanachellam CJ. Effect of Swiss ball training on cardiovascular endurance and abdominal strength of physical education students. International Journal of Physiology, Nutrition and Physical Education 2018; 3(1): 1378-81.

[25] Coulombe BJ, Games KE, Neil ER, Eberman LE. Core stability exercise versus general exercise for chronic low back pain. Journal of Athletic Training. 2017; 52(1):71-2. [DOI:10.4085/1062-6050-51.11.16] [PMID] [PMCID]

[26] Liebenson C. Functional training part 1: New advances, Journal of Bodywork and Movement Therapies. 2002; 6(4):248-54. [DOI:10.1054/jbmt.2002.0311]

[27] Mohammadi V, Hilfiker R, Jafarnezhadgero AA, Jamialahmadi S, Ardakani MK, Granacher U. Relationship between training-induced changes in the Star Excursion Balance Test and the $Y$ balance test in young male athletes. Annals of Applied Sport Science. 2017; 5(3):31-8. [DOI:10.29252/acadpub. aassjournal.5.3.31]

[28] Sandrey MA, Mitzel JG. Improvement in dynamic balance and core endurance after a 6-week core-stability-training program in high school track and field athletes. Journal of Sport Rehabilitation. 2013; 22(4):264-71. [DOI:10.1123/ jsr.22.4.264] [PMID]

[29] Bavardi Moghadam E, Shojaedin SS, Radfar H. Effect of Pilates training on functional balance of elderly men. Journal of Gorgan University of Medical Sciences. 2018; 20(3):64-9.

[30] Hodges PW. Core stability exercise in chronic low back pain. Orthopedic Clinics. 2003; 34(2):245-54. [DOI:10.1016/ S0030-5898(03)00003-8]

[31] Wang XQ, Zheng JJ, Yu ZW, Bi X, Lou SJ, Liu J, et al. A meta-analysis of core stability exercise versus general exercise for chronic low back pain. PloS One. 2012; 7(12):e52082. [DOI:10.1371/journal.pone.0052082] [PMID] [PMCID]

[32] McCaskey A. The effects of core stability training on star excursion balance test and global core muscular endurance [MSc. thesis]. Toledo, Ohio: University of Toledo; 2011.

[33] Carpes FP, Reinehr FB, Mota CB. Mota, Effects of a program for trunk strength and stability on pain, low back and pelvis kinematics, and body balance: A pilot study. Journal of Bodywork and Movement Therapies. 2008; 12(1):22-30. [DOI:10.1016/j.jbmt.2007.05.001] [PMID]

[34] Mills DJ, Taunton JE, Mills WA. The effect of a 10-week training regimen on lumbo-pelvic stability and athletic per- formance in female athletes: A randomized-controlled trial. Physical Therapy in Sport. 2005; 6(2):60-6. [DOI:10.1016/j. ptsp.2005.02.006]

[35] Gordon AT, Ambegaonkar JP, Caswell SV. Relationships between core strength, hip external rotator muscle strength, and star excursion balance test performance in female lacrosse players. International Journal of Sports Physical Therapy. 2013; 8(2):97-104. [PMID] [PMCID]

[36] Filipa, A., et al., Neuromuscular training improves performance on the star excursion balance test in young female athletes. Journal of Orthopaedic \& Sports Physical Therapy, 2010; 40(9):551-8. [DOI:10.2519/jospt.2010.3325] [PMID] [PMCID]

[37] Gribble PA, Hertel J. Considerations for normalizing measures of the star excursion balance test. Measurement in Physical Education and Exercise Science. 2003; 7(2):89-100. [DOI:10.1207/S15327841MPEE0702_3]

[38] Olmsted LC, Carcia CR, Hertel J, Shultz SJ. Efficacy of the star excursion balance tests in detecting reach deficits in subjects with chronic ankle instability. Journal of Athletic Training. 2002; 37(4):501-6. [PMID] [PMCID]

[39] Earl JE, Hertel J. Lower-extremity muscle activation during the star excursion balance tests. Journal of Sport Rehabilitation. 2001; 10(2):93-104. [DOI:10.1123/jsr.10.2.93]

[40] Yoon SD, Sung DH, Park GD. The effect of active core exercise on fitness and foot pressure in Taekwondo club students. Journal of Physical Therapy Science. 2015; 27(2):509-11. [DOI:10.1589/jpts.27.509] [PMID] [PMCID] 
This Page Intentionally Left Blank 